\title{
Rapid detection of FMO3 single nucleotide polymorphisms using a pyrosequencing method
}

\author{
JIN-WOO PARK ${ }^{1,2}$, IN-HWAN PARK $^{1}$, JONG-MIN KIM $^{1}$, JI HYEON NOH ${ }^{1}$, \\ KYOUNG-AH KIM ${ }^{1}$ and JI-YOUNG PARK ${ }^{1}$
}

${ }^{1}$ Department of Clinical Pharmacology and Toxicology, Korea University College of Medicine, Korea University Anam Hospital; ${ }^{2}$ Department of Neurology, Korea University Medical Center, Seoul 02841, Republic of Korea

Received July 30, 2021; Accepted November 11, 2021

DOI: $10.3892 / \mathrm{mmr} .2021 .12564$

\begin{abstract}
The present study aimed to develop a reliable pyrosequencing method to detect four single nucleotide polymorphisms (SNPs) of the flavin-containing monooxygenase 3 (FMO3) gene and to compare the ethnic differences in their allelic frequencies. The pyrosequencing method was used to detect four FMO3 SNPs, namely, c.855C $>$ T $(\mathrm{N} 285 \mathrm{~N}$, rs909530), c.441C >T (S147S, rs1800822), c.923A>G (E308G, rs2266780) and c.472G $>$ A (E158K, rs2266782). The allelic frequencies of these SNPs in 122 unrelated Korean subjects were as follows: i) $44.7 \%$ for c. $855 \mathrm{C}>\mathrm{T}$; ii) $23.4 \%$ for c. $441 \mathrm{C}>\mathrm{T}$; iii) $23.0 \%$ for c. $923 \mathrm{~A}>\mathrm{G}$; and iv) $27.1 \%$ for c. $472 \mathrm{G}>\mathrm{A}$. Linkage disequilibrium (LD) analysis revealed that the SNPs c.923A $>\mathrm{G}$ and $c .472 \mathrm{G}>\mathrm{A}$ exhibited a strong $\mathrm{LD}\left(\mathrm{D}^{\prime}=0.8289, \mathrm{r}^{2}=0.5332\right)$. In conclusion, the pyrosequencing method developed in this study was successfully applied to detect the c.855C $>\mathrm{T}$, c. $441 \mathrm{C}>\mathrm{T}$, c. $923 \mathrm{~A}>\mathrm{G}$ and c. $472 \mathrm{G}>\mathrm{A}$ SNPs of $F M O 3$.
\end{abstract}

\section{Introduction}

Flavin-containing monooxygenases (FMOs) form a family of microsomal antioxidant defense enzymes responsible for nicotinamide adenine dinucleotide phosphate-dependent oxygenation of soft nucleophiles $(1,2)$. Five functional isoforms of FMO have been identified in humans (FMO1-5) (2). FMO3, primarily located in the liver, is the second most common FMO that metabolizes various nitrogen- and sulfur-containing drugs and exhibits a broad range of substrates (3-5). The FMO3 gene is clustered on chromosome 1 (q24.3) and contains nine exons ranging from 80 to $705 \mathrm{bp}$ (2). Several genetic polymorphisms

Correspondence to: Professor Ji-Young Park, Department of Clinical Pharmacology and Toxicology, Korea University College of Medicine, Korea University Anam Hospital, 73 Inchon-ro, Seongbuk, Seoul 02841, Republic of Korea

E-mail: jypark21@korea.ac.kr

Key words: pyrosequencing, c.855C $>\mathrm{T}$, c.441C $>\mathrm{T}$, c.923A $>\mathrm{G}$, c. $472 \mathrm{G}>\mathrm{A}$, flavin-containing monooxygenase 3 have been identified in this region (2). Moreover, previous studies have reported genetic polymorphisms of FMO3 that affect the enzyme activity and plasma concentrations of certain medications, and diseases such as trimethylaminuria (6-8). Of these polymorphisms, the c.855C $>\mathrm{T}(\mathrm{N} 285 \mathrm{~N}$, rs909530), c.441C >T (S147S, rs1800822), c.923A > G (E308G, rs2266780) and c.472G $>$ A (E158K, rs2266782) mutations are commonly detected single nucleotide polymorphisms (SNPs) in East Asian populations (9-12). Considering their clinical importance and prevalence, there is a need to investigate the differences in the allelic frequencies of these polymorphisms between various ethnic groups and develop a reliable method for such analysis, which could be applied for optimal subject group targeting in clinical practice (8).

In the present study, a rapid and reliable pyrosequencing method was developed to detect SNPs of the FMO3 gene, including two synonymous (c.855C $>\mathrm{T}$ and c. $441 \mathrm{C}>\mathrm{T}$ ) and two non-synonymous (c.923A $>\mathrm{G}$ and c.472G $>\mathrm{A}$ ) variants, all of which are clinically important and common in the Korean population $(13,14)$. Additionally, this study aimed to compare the allelic frequencies of these SNPs in a Korean population with those reported in other ethnic groups.

\section{Materials and methods}

Subjects and methods. This study was conducted in Korea University Anam Hospital (Seoul, Korea) between April 2017 and February 2020. Genomic DNA was extracted from the blood samples of 122 unrelated healthy Korean subjects (age: 20-45, all male participants) who provided written informed consent to participate in this study. The protocol for this assay was approved by the institutional review board of Anam Hospital, Korea University Medical Center (IRB approval no. 2017AN0117, Seoul, South Korea).

Polymerase chain reaction (PCR) conditions and FMO3 genotyping using pyrosequencing. Genomic DNA was extracted from peripheral blood leukocytes as previously described (15). GeneAll ${ }^{\circledR}$ Exgene Blood SV kit (GeneAll) was used according to the manufacturer's instructions. DNA quantification was processed by using Biospec-Nano (Shimadzu, Kyoto, Japan). A pyrosequencing method was developed to detect the func- 
tional SNPs of the $F M O 3$ gene: c. $855 \mathrm{C}>\mathrm{T}, \mathrm{c} .441 \mathrm{C}>\mathrm{T}, \mathrm{c} .923 \mathrm{~A}>\mathrm{G}$ and c. $472 \mathrm{G}>\mathrm{A}$. PCR primers used for $F M O 3$ genotyping and pyrosequencing are listed in Table I. PCR was performed to amplify the specific sequences and detect each SNP of FMO3 using the newly developed primer sets after tagging the $5^{\prime}$ end of each forward (or reverse) primer with biotin using the PSQ Assay Design software (version 2.0; Qiagen $\mathrm{GmbH}$ ).

The PCR mixture $(30 \mu \mathrm{l})$ comprised genomic DNA (30 ng), 10X PCR buffer (Intron Biotechnology, Inc.), dNTPs $(0.25 \mathrm{mM}), 10$ pmol primers $(1 \mu \mathrm{l}$ each) and 5 units Taq polymerase (Intron Biotechnology, Inc.). PCR was performed with an initial denaturation step at $95^{\circ} \mathrm{C}$ for $3 \mathrm{~min}$, followed by 45 cycles of denaturation at $95^{\circ} \mathrm{C}$ for $30 \mathrm{sec}$, annealing at $60^{\circ} \mathrm{C}$ for $30 \mathrm{sec}$, and extension at $72^{\circ} \mathrm{C}$ for $30 \mathrm{sec}$. The final termination step was performed at $72^{\circ} \mathrm{C}$ for $5 \mathrm{~min}$. For pyrosequencing reactions, $25 \mu \mathrm{l}$ PCR template in a single well was immobilized by incubation (with continuous shaking at $1,400 \mathrm{rpm}$ for $10 \mathrm{~min}$ at room temperature) with a mixture of $5 \mu 1$ streptavidin beads (Streptavidin Sepharose ${ }^{\mathrm{TM}}$ High Performance; Cytiva) and $40 \mu \mathrm{l}$ annealing buffer containing $0.4 \mu \mathrm{M}$ sequencing primer incorporated into each well. For strand separation, the liquid component was removed using a vacuum prep workstation (Qiagen $\mathrm{GmbH}$ ). The beads captured on the probes were treated in $70 \%$ ethanol, and the solution was passed through a filter for $5 \mathrm{sec}$. The beads were then treated with a denaturing solution $(0.2 \mathrm{M} \mathrm{NaOH})$, and the solution was passed through a filter for $5 \mathrm{sec}$. Thereafter, a wash buffer (10 mM Tris-acetate, $\mathrm{pH}$ 7.6) was used to rinse the beads for $5 \mathrm{sec}$. The liquid component was completely removed from the probes, and the beads were placed into a PSQ 96 Plate Low (Pyrosequencing $\mathrm{AB}$ ) containing the sequencing primer. The prepared PSQ 96 Plate Low was heated at $85^{\circ} \mathrm{C}$ for $2 \mathrm{~min}$, and the reactions were allowed to cool to room temperature. The resulting mixture was analyzed using the PSQ 96MA pyrosequencer (Pyrosequencing AB). The accuracy of pyrosequencing was validated by direct DNA sequencing of randomly selected samples using the same genomic DNA. The analyzed allelic frequencies were then compared with those of other ethnic groups and those reported in the HapMap database (https://www.ncbi.nlm.nih.gov/snp).

Statistical analysis. Genetic equilibrium and linkage disequilibrium (LD) were tested according to the Hardy-Weinberg equation (HWE) (16) using SNPalyzer software (version 9.0; DYNACOM Co., Ltd.). A chi-square test was performed to assess the deviation of the pyrosequencing results from the HWE. The detected genotype frequencies were then compared to the expected frequencies. $\mathrm{P}<0.05$ (two-tailed) was considered to indicate a statistically significant difference. $\mathrm{D}^{\prime}$ and $\mathrm{r}^{2}$ are standard measurements for the LD (17). D' values were calculated as $\mathrm{D} / \mathrm{D}_{\max }$, where $\mathrm{D}$ is the coefficient of $\mathrm{LD}$ ranging from -0.25 to 0.25 . In general, the standardized value of $D^{\prime}$ is preferred because $\mathrm{D}$ is often affected by allelic frequencies (18).

\section{Results}

Each FMO3 SNP, including c.855C $>$ T, c. $441 \mathrm{C}>\mathrm{T}$, c. $923 \mathrm{~A}>\mathrm{G}$ and c. $472 \mathrm{G}>\mathrm{A}$, was successfully detected, as shown in the predicted pyrosequencing histogram (Fig. 1). Representative peaks for each SNP are shown in Fig. 2. The sequenced data obtained using the pyrosequencing method were randomly selected and validated by direct DNA sequencing. The results were $100 \%$ concordant with the pyrosequencing data, indicating $100 \%$ specificity and sensitivity (data not shown).

The allelic frequencies of FMO3 SNPs in the Korean population obtained using our pyrosequencing method were as follows: i) $44.7 \%$ for c. $855 \mathrm{C}>\mathrm{T}$; ii) $23.4 \%$ for c. $441 \mathrm{C}>\mathrm{T}$; iii) $23.0 \%$ for c. $923 \mathrm{~A}>\mathrm{G}$; and iv) $27.1 \%$ for c. $472 \mathrm{G}>\mathrm{A}$ (Table II). The allelic frequencies obtained in these genetic analyses did not deviate from the Hardy-Weinberg equilibrium $\left(\chi^{2}=0.1843\right.$, $0.1201,0.0318$ and 0.4729 for c. $855 \mathrm{C}>\mathrm{T}, \mathrm{c} .441 \mathrm{C}>\mathrm{T}, \mathrm{c} .923 \mathrm{~A}>\mathrm{G}$ and c. $472 \mathrm{G}>\mathrm{A}$, respectively; $\mathrm{P}=0.6677,0.7290,0.8584$ and 0.4917 for c. $855 \mathrm{C}>\mathrm{T}$, c. $441 \mathrm{C}>\mathrm{T}, \mathrm{c} .923 \mathrm{~A}>\mathrm{G}$ and c. $472 \mathrm{G}>\mathrm{A}$, respectively); however, the $\mathrm{LD}$ analysis revealed that c. $923 \mathrm{~A}>\mathrm{G}$ and c. $472 \mathrm{G}>\mathrm{A}$ exhibited strong $\mathrm{LD}\left(\mathrm{D}^{\prime}=0.8289\right.$, $r^{2}=0.5332$; Table SI).

The ethnic differences of the SNPs were described in Table III. Although the data were limited, particularly for the European and African populations; however, the trend of the allelic frequencies for FMO3 SNPs obtained in the present study was similar to that previously reported in a Japanese population (12). In particular, the allelic frequencies of c.923A $>\mathrm{G}$ and c. $472 \mathrm{G}>\mathrm{A}$ appeared to be similar to those in the Chinese population (3). The SNP c.923A $>$ G frequency exhibited some similarity to the minor allele frequency (MAF) of the HapMap data of Europeans (Utah residents with Northern and Western European ancestry from the CEPH collection reported by the National Center for Biotechnology Information SNP database; HapMap-CEU; https://www.ncbi.nlm.nih.gov/snp), whereas the frequencies of other SNPs exhibited remarkable differences from the MAF of this population.

\section{Discussion}

The results of the present study indicated that this newly developed rapid pyrosequencing method for analyzing the c. $855 \mathrm{C}>\mathrm{T}, \mathrm{c} .441 \mathrm{C}>\mathrm{T}, \mathrm{c} .923 \mathrm{~A}>\mathrm{G}$ and c. $472 \mathrm{G}>\mathrm{A}$ SNPs of the $F M O 3$ gene was a reliable and accurate technique. The allelic frequencies obtained in 122 Korean subjects using this method revealed that these frequencies were most similar to those reported in the Japanese population (12). To the best of our knowledge, this was the first study to analyze FMO3 SNPs using a pyrosequencing method.

Various methods have been proposed to analyze the targeted SNPs. For example, FMO3-related SNPs have been detected by using PCR-restriction fragment length polymorphism analysis (19), real-time PCR (20) and direct sequencing methods (21). Sequencing technology was first conceptualized and developed in the 1970s by Sanger et al (22). The principle of this method is based on the use of dideoxynucleotide triphosphates for DNA sequence termination. The pyrosequencing method that was designed to analyze FMO3 SNPs in the current study was based on the solution-based pyrosequencing method suggested by Ronaghi et al (23) in 1998. This is a simple method that is suitable for automation as it uses apyrase, DNA polymerase and luciferase, which eventually detect light emission through pyrophosphate production during DNA synthesis (23). The major advantages of this method are its simplicity, reliability, high sensitivity and specificity compared 
Table I. Oligonucleotide primers used for PCR and pyrosequencing to detect FMO3 SNPs.

\begin{tabular}{|c|c|c|c|c|}
\hline SNP & Primer & Sequences & Size, bp & PCR Tm, ${ }^{\circ} \mathrm{C}$ \\
\hline$F M O 3$ c. $855 \mathrm{C}>\mathrm{T}(\mathrm{rs} 909530)$ & $\begin{array}{l}\text { Forward } \\
\text { Reverse } \\
\text { Sequencing }\end{array}$ & $\begin{array}{l}\text { B 5'-TTGGGTCATTTTTTCCTTCCTTAT-3' } \\
\text { 5'-ACCCTGTTGCAAAGATTACACAGT-3' } \\
\text { 5'-TTGCTGGGAGCTCAT-3' }\end{array}$ & 261 & 60 \\
\hline FMO3 c.441C $>\mathrm{T}(\mathrm{rs} 1800822)$ & $\begin{array}{l}\text { Forward } \\
\text { Reverse } \\
\text { Sequencing }\end{array}$ & $\begin{array}{l}\text { B 5'-CCACTGAAAGGGATGGTAAAAA-3' } \\
\text { 5'-AGCAGCTTAAATTTTGGCCTTAC-3' } \\
\text { 5'-TGGGATACACATGATGTC-3' }\end{array}$ & 125 & 60 \\
\hline FMO3 с. $923 \mathrm{~A}>\mathrm{G}(\mathrm{rs} 2266780)$ & $\begin{array}{l}\text { Forward } \\
\text { Reverse } \\
\text { Sequencing }\end{array}$ & $\begin{array}{l}\text { 5'-AGCATTCTGTGTGGCATTGT-3' } \\
\text { B 5'-AAGGAAGGGGTAGGCAAAACTAT-3' } \\
\text { 5'-CGTGAAGGAATTCACAG-3' }\end{array}$ & 144 & 60 \\
\hline FMO3 c. $472 \mathrm{G}>\mathrm{A}(\mathrm{rs} 2266782)$ & $\begin{array}{l}\text { Forward } \\
\text { Reverse } \\
\text { Sequencing }\end{array}$ & $\begin{array}{l}\text { B 5'-ATGGTAAAAAAGAATCGGCTGTC-3' } \\
\text { 5'-TTTTGTCAGTTATGTGGCTAGCAG-3' } \\
\text { 5'-GCCTTACCTGGAAAGGACT-3' }\end{array}$ & 132 & 60 \\
\hline
\end{tabular}

FMO3, flavin-containing monooxygenase 3; SNP, single nucleotide polymorphism; PCR, polymerase chain reaction; B, biotinylated at the end of the primer; Tm, melting temperature.
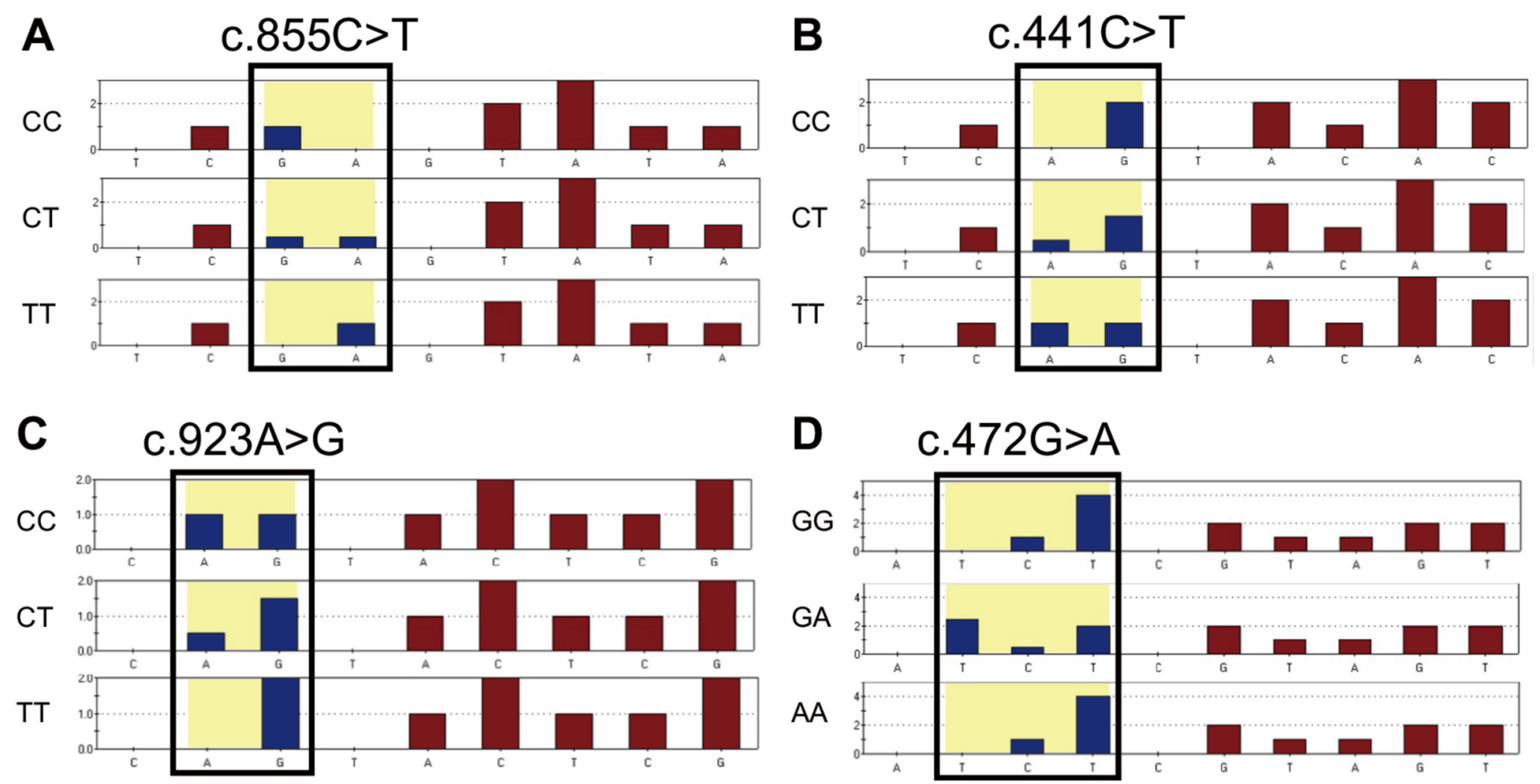

Figure 1. Predesigned predicted histograms of $F M O 3$ SNPs generated using the pyrosequencing software. (A) c.855C $>\mathrm{T}$, (B) c.441C $>\mathrm{T},(\mathrm{C}) \mathrm{c} .923 \mathrm{~A}>\mathrm{G}$ and (D) c.472G $>$ A SNPs of the FMO3 gene. Area under the black box indicates the detected polymorphism site. FMO3, flavin-containing monooxygenase 3; SNPs, single nucleotide polymorphisms.

with conventional sequencing systems (24). Therefore, it was speculated that the method described in the present study could be suitable for precise, rapid and cost-effective assessment of SNP frequencies in a relatively large sample set.

SNPs are the most frequently occurring sequence variations in the human genome and often vary among different ethnic groups $(1,2)$. The allelic frequencies of selected FMO3 SNPs observed in this study were comparable to those reported in the Japanese population (9), whereas the frequency of each genotype in the Chinese population was generally lower than that in the Korean or Japanese populations $(3,12)$.
FMO3 c.855C $>$ T was the most commonly detected SNP in the current study; this result was consistent with that previously reported in a smaller Korean population previously $(n=41, M A F=0.329)(13)$. The frequencies of the $c .855 C>T$ and c.472G $>$ A SNPs were higher in the African population (HapMap-YRI database; https://www.ncbi.nlm.nih.gov/snp,32) than in the Asian populations; however, the frequencies of c. $441 \mathrm{C}>\mathrm{T}$ and c.923A $>\mathrm{G}$ in the African population were markedly lower (<5\%) (HapMap-YRI database; https://www. ncbi.nlm.nih.gov/snp). Therefore, FMO3 appears to exhibit a large interethnic difference $(3,9,13)$. 
Table II. Genotyping and allelic frequencies of FMO3 SNPs identified in this study.

$\mathrm{A}, \mathrm{c} .855 \mathrm{C}>\mathrm{T}$

\begin{tabular}{|c|c|c|c|c|c|c|}
\hline Genotype & Counts & Genotyping frequency & Allele & Allelic frequency & $\chi^{2}$ & P-value \\
\hline $\mathrm{G} / \mathrm{G}$ & 36 & 0.2951 & $\mathrm{G}$ & 0.5533 & 0.1843 & 0.6677 \\
\hline $\mathrm{G} / \mathrm{A}$ & 63 & 0.5164 & A & 0.4467 & & \\
\hline $\mathrm{A} / \mathrm{A}$ & 23 & 0.1885 & & & & \\
\hline
\end{tabular}

B, c. $441 \mathrm{C}>\mathrm{T}$

\begin{tabular}{lccccc}
\hline Genotype & Counts & Genotyping frequency & Allele & Allelic frequency & $\chi^{2}$ \\
\hline G/G & 70 & 0.5738 & G & 0.7664 & 0.1201 \\
G/A & 47 & 0.3852 & A & 0.2336 & 0.7290 \\
A/A & 5 & 0.0410 & & & \\
\hline
\end{tabular}

C, c. $923 \mathrm{~A}>\mathrm{G}$

\begin{tabular}{|c|c|c|c|c|c|c|}
\hline Genotype & Counts & Genotyping frequency & Allele & Allelic frequency & $\chi^{2}$ & P-value \\
\hline $\mathrm{A} / \mathrm{A}$ & 72 & 0.5901 & $\mathrm{~A}$ & 0.7705 & 0.0318 & 0.8584 \\
\hline $\mathrm{A} / \mathrm{G}$ & 44 & 0.3607 & $\mathrm{G}$ & 0.2295 & & \\
\hline $\mathrm{G} / \mathrm{G}$ & 6 & 0.0492 & & & & \\
\hline
\end{tabular}

D, c. $472 \mathrm{G}>\mathrm{A}$

\begin{tabular}{lccccc}
\hline Genotype & Counts & Genotyping frequency & Allele & Allelic frequency & $\chi^{2}$ \\
\hline C/C & 63 & 0.5164 & $\mathrm{C}$ & 0.7295 & 0.4729 \\
$\mathrm{C} / \mathrm{T}$ & 52 & 0.4262 & $\mathrm{~T}$ & 0.2705 & 0.4917 \\
$\mathrm{~T} / \mathrm{T}$ & 7 & 0.0574 & & &
\end{tabular}

The expected and observed frequencies were compared using the Hardy-Weinberg equation. FMO3, flavin-containing monooxygenase 3; SNP, single nucleotide polymorphism.

A

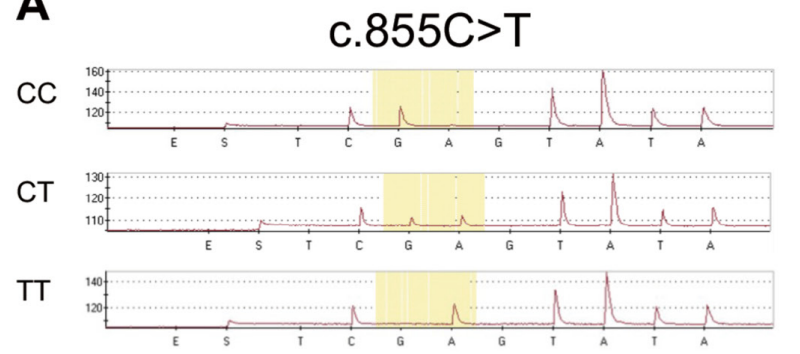

C

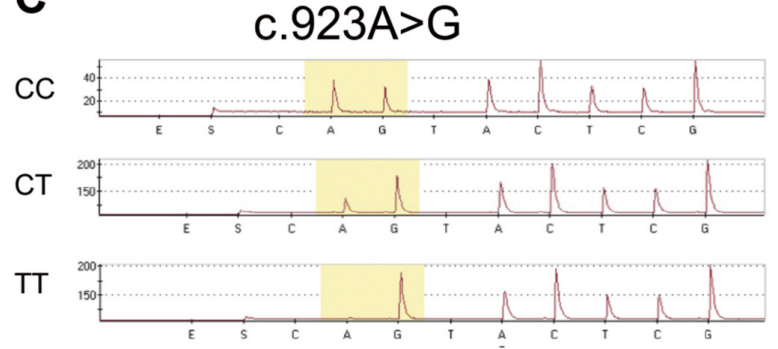

B

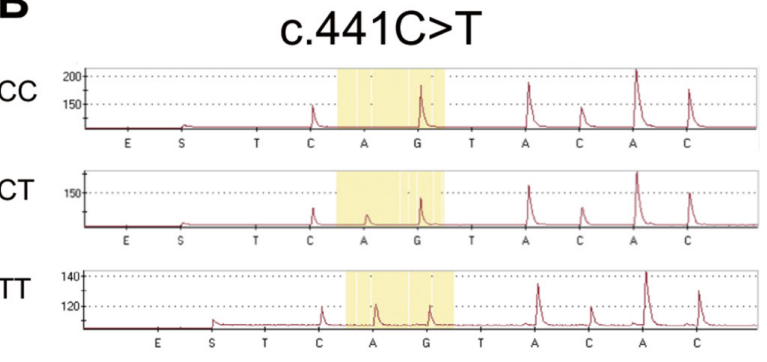

D

c. $472 \mathrm{G}>\mathrm{A}$

GG

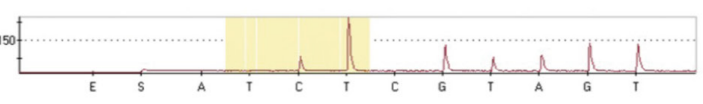

GA

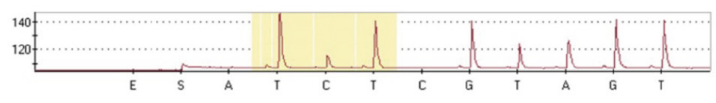

AA

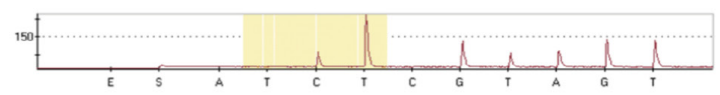

Figure 2. Representative pyrograms of flavin-containing monooxygenase 3 single nucleotide polymorphisms. Yellow highlights show (A) c.855C $>\mathrm{T}$, (B) c. $441 \mathrm{C}>\mathrm{T}$, (C) $c .923 \mathrm{~A}>\mathrm{G}$ and (D) $c .472 \mathrm{G}>\mathrm{A}$ identified using the established pyrosequencing method. 
Table III. Comparisons between FMO3 allele frequencies obtained in this study and those in other ethnic groups.

\begin{tabular}{lccc}
\hline A, c.855C $>\mathrm{T}$ & & & \\
\hline Population & Number, $\mathrm{n}$ & MAF, \% & Refs. \\
\hline Korean & 122 & 44.7 & Present study \\
Japanese & 3,552 & 38.8 & $(12)$ \\
Chinese & 285 & 26.1 & $(3)$ \\
European & 226 & 27.9 & HapMap-CEU database \\
Sub-Saharan African & 226 & 54.0 & HapMap-YRI database \\
\hline
\end{tabular}

B, c. $441 \mathrm{C}>\mathrm{T}$

\begin{tabular}{lccc}
\hline Population & Number, $\mathrm{n}$ & MAF, $\%$ & Refs. \\
\hline Korean & 122 & 23.4 & Present study \\
Japanese & 3,552 & 19.9 & $(12)$ \\
Chinese & 285 & 5.8 & $(3)$ \\
European & 226 & 6.6 & HapMap-CEU database \\
Sub-Saharan African & 226 & 3.1 & HapMap-YRI database \\
\hline
\end{tabular}

C, c. $923 \mathrm{~A}>\mathrm{G}$

\begin{tabular}{lccr}
\hline Population & Number, $n$ & MAF, $\%$ & Refs. \\
\hline Korean & 122 & 23.0 & Present study \\
Japanese & 3,552 & 19.8 & $(12)$ \\
Chinese & 285 & 19.8 & $(3)$ \\
European & 170 & 35.9 & $(31)$ \\
Sub-Saharan African & 226 & 1.3 & HapMap-YRI database
\end{tabular}

$\mathrm{D}, \mathrm{c} .472 \mathrm{G}>\mathrm{A}$

\begin{tabular}{lccr}
\hline Population & Number, $n$ & MAF, $\%$ & Refs. \\
\hline Korean & 122 & 27.1 & Present study \\
Japanese & 3,552 & 21.0 & $(12)$ \\
Chinese & 285 & 16.5 & $(3)$ \\
European & 224 & 42.0 & HapMap-CEU database \\
African-American & 133 & 41.9 & $(32)$
\end{tabular}

FMO3, flavin-containing monooxygenase 3; MAF, minor allele frequency; CEU, Utah residents with Northern and Western European ancestry from the CEPH collection; YRI, Yoruba in Ibadan, Nigeria.

FMO3 genetic polymorphisms have been the focus of considerable interest in research; these findings can be applied to various studies on the pharmacokinetics of various medications, including anti-diabetics (e.g., teneligliptin) $(5,6)$, antibiotics (e.g., voriconazole) $(20,25)$ and non-steroidal anti-inflammatory drugs (e.g., sulindac) $(4,13,14)$, as well as human diseases, such as cardiovascular disorders (2,7). FMO3 increases plasma trimethylamine $\mathrm{N}$-oxide (TMAO) levels by catalyzing the conversion of trimethylamine (TMA) derived from the gut microbiome $(26,27)$. Therefore, SNPs responsible for FMO3 loss-of-function seem to result in increased plasma
TMA levels (9). At a clinical level, TMAO is associated with atherosclerosis (28), and a recent study demonstrated that higher plasma TMAO levels were associated with poor cardiovascular outcomes, while the FMO3 SNP (c.472G>A) has been shown to reduce TMAO levels in the Asian population (7).

FMO3 also affects the levels of several clinically important medications, and its polymorphisms are associated with drug toxicity $(25,29,30)$. The c.923A $>$ G SNP has been shown to increase voriconazole concentrations by reducing FMO3 enzyme activity (25), while c.855C $>\mathrm{T}$ SNP can increase the concentration of teneligliptin (6). FMO3 c.441C $>$ T and 
c.855C $>\mathrm{T}$ have been associated with fast tacrolimus elimination in Chinese patients (30). Studies by Park et al (13) and Sung et al (14) demonstrated that the SNPs c.855C $>\mathrm{T}$ and c.472G $>$ A affected the pharmacokinetics of sulindac in women who underwent preterm labor. Febrile neutropenia, myelosuppression and agranulocytosis related to these SNPs have also been reported previously $(25,29,30)$.

Considering the relatively high frequency of FMO3 genetic polymorphisms in the population, the functional defects in FMO3 enzymes associated with these SNPs may have notable clinical implications, such as the variations in drug exposure followed by toxicity or delayed elimination of toxic substances. Therefore, the development of a faster and more precise method to identify FMO3 SNPs could be clinically beneficial when purposed for optimal treatment (e.g., suggesting lower dosage in the patients with FMO3 genetic polymorphism to reduce the drug toxicity and adverse events). However, evidence should be accumulated through clinical studies.

The ethnic and interindividual differences in SNPs and their suspected clinical manifestations, personalized dosing, pharmacokinetics and pharmacodynamics studies of drugs based on FMO3 SNPs may present a novel research direction. Thus, the pyrosequencing method developed in this study could be applied directly to analyze individual FMO3 SNPs for research in this domain.

In conclusion, the pyrosequencing method developed in the present study was successfully applied to detect the SNPs c. $855 \mathrm{C}>\mathrm{T}, \mathrm{c} .441 \mathrm{C}>\mathrm{T}, \mathrm{c} .923 \mathrm{~A}>\mathrm{G}$ and c. $472 \mathrm{G}>\mathrm{A}$ of the $F M O 3$ gene. In Korean subjects, c.855C $>\mathrm{T}$ was the most frequent among the four FMO3 SNPs.

\section{Acknowledgements}

Not applicable.

\section{Funding}

No funding was received.

\section{Availability of data and materials}

The datasets generated and/or analyzed during the current study are not publicly available due to information that could compromise the privacy of research participants, but are available from the corresponding author upon reasonable request.

\section{Authors' contributions}

JWP was responsible for data acquisition, analysis and interpretation, and drafting of the article. JYP conceptualized and co-designed the study, critically screened the revised article for important intellectual content, and provided final approval of the submitted manuscript. KAK designed the study, and performed data analysis and interpretation. IHP, JMK and JHN were responsible for data acquisition and analysis. JWP and JYP confirm the authenticity of all the raw data. All authors have read and approved the final manuscript.

\section{Ethics approval and consent to participate}

The protocol for this assay was approved by the Institutional Review Board of Anam Hospital, Korea University Medical Center (Seoul, South Korea). Subjects provided written informed consent to participate in this study.

\section{Patients consent for publication}

Not applicable.

\section{Competing interests}

The author declare that they have no competing interests.

\section{References}

1. Phillips IR and Shephard EA: Drug metabolism by flavincontaining monooxygenases of human and mouse. Expert Opin Drug Metab Toxicol 13: 167-181, 2017.

2. Phillips IR and Shephard EA: Flavin-containing monooxygenase 3 (FMO3): Genetic variants and their consequences for drug metabolism and disease. Xenobiotica 50: 19-33, 2020.

3. $\mathrm{Xu} M$, Bhatt DK, Yeung CK, Claw KG, Chaudhry AS, Gaedigk A, Pearce RE, Broeckel U, Gaedigk R, Nickerson DA, et al: Genetic and nongenetic factors associated with protein abundance of flavin-containing monooxygenase 3 in human liver. J Pharmacol Exp Ther 363: 265-274, 2017.

4. Tang YJ, Hu K, Huang WH, Wang CZ, Liu Z, Chen Y, Ouyang DS, Tan ZR, Zhou HH and Yuan CS: Effects of FMO3 polymorphisms on pharmacokinetics of sulindac in Chinese healthy male volunteers. BioMed Res Int 2017: 4189678, 2017.

5. Ceriello A, De Nigris V, Iijima H, Matsui T and Gouda M: The unique pharmacological and pharmacokinetic profile of teneligliptin: Implications for clinical practice. Drugs 79: 733-750, 2019.

6. Park JW, Kim KA, Kim JM, Park IH and Park JY: Influence of FMO3 and CYP3A4 polymorphisms on the pharmacokinetics of teneligliptin in humans. Front Pharmacol 12: 736317, 2021.

7. Wei H, Zhao M, Huang M, Li C, Gao J, Yu T, Zhang Q, Shen $\mathrm{X}$, Ji L, Ni L, et al: FMO3-TMAO axis modulates the clinical outcome in chronic heart-failure patients with reduced ejection fraction: evidence from an Asian population. Front Med: Jun 22, 2021 (Epub ahead of print). doi: 10.1007/s11684021-0857-2.

8. Scimone C, Alibrandi S, Donato L, Giofrè SV, Rao G, Sidoti A and D'Angelo R: Antiretroviral treatment leading to secondary trimethylaminuria: Genetic associations and successful management with riboflavin. J Clin Pharm Ther 46: 304-309, 2021.

9. Shimizu M, Allerston CK, Shephard EA, Yamazaki H and Phillips IR: Relationships between flavin-containing mono-oxygenase 3 (FMO3) genotype and trimethylaminuria phenotype in a Japanese population. Br J Clin Pharmacol 77: 839-851, 2014.

10. Shimizu M, Kobayashi Y, Hayashi S, Aoki Y and Yamazaki H: Variants in the flavin-containing monooxygenase 3 (FMO3) gene responsible for trimethylaminuria in a Japanese population. Mol Genet Metab 107: 330-334, 2012.

11. Shimizu M, Yoda H, Igarashi N, Makino M, Tokuyama E and Yamazaki H: Novel variants and haplotypes of human flavin-containing monooxygenase 3 gene associated with Japanese subjects suffering from trimethylaminuria. Xenobiotica 49: 1244-1250, 2019.

12. Shimizu M, Yoda H, Nakakuki K, Saso A, Saito I, Hishinuma E, Saito S, Hiratsuka M and Yamazaki H: Genetic variants of flavin-containing monooxygenase 3 (FMO3) derived from Japanese subjects with the trimethylaminuria phenotype and whole-genome sequence data from a large Japanese database. Drug Metab Pharmacokinet 34: 334-339, 2019.

13. Park S, Lee NR, Lee KE, Park JY, Kim YJ and Gwak HS: Effects of single-nucleotide polymorphisms of FMO3 and FMO6 genes on pharmacokinetic characteristics of sulindac sulfide in premature labor. Drug Metab Dispos 42: 40-43, 2014. 
14. Sung JW, Yun HY, Park S, Kim YJ, Yee J, Lee KE, Song B, Chung JE and Gwak HS: Population pharmacokinetics of sulindac and genetic polymorphisms of FMO3 and AOX1 in women with preterm labor. Pharm Res 37: 44, 2020.

15. Kwak HD, Kim SH, Seo YS and Song KJ: Detecting hepatitis B virus in surgical smoke emitted during laparoscopic surgery. Occup Environ Med 73: 857-863, 2016.

16. Abramovs N, Brass A and Tassabehji M: Hardy-weinberg equilibrium in the large scale genomic sequencing era. Front Genet 11: 210, 2020.

17. Du FX, Clutter AC and Lohuis MM: Characterizing linkage disequilibrium in pig populations. Int J Biol Sci 3: 166-178, 2007

18. Sunderaraman P, Cosentino S, Schupf N, Manly J, Gu Y and Barral S: MEF2C common genetic variation is associated with different aspects of cognition in non-hispanic white and caribbean hispanic non-demented older adults. Front Genet 12: 642327, 2021.

19. Shimizu M, Mizugaki A, Koibuchi N, Sango H, Uenuma Y and Yamazaki H: A series of simple detection systems for genetic variants of flavin-containing monooxygenase 3 (FMO3) with impaired function in Japanese subjects. Drug Metab Pharmacokinet 41: 100420, 2021.

20. Chuwongwattana S, Jantararoungtong T, Prommas S, Medhasi S, Puangpetch A and Sukasem C: Impact of CYP2C19, CYP3A4 $\mathrm{ABCB} 1$, and FMO3 genotypes on plasma voriconazole in Thai patients with invasive fungal infections. Pharmacol Res Perspect 8: e00665, 2020.

21. D'Angelo R, Scimone C, Esposito T, Bruschetta D, Rinaldi C, Ruggeri A and Sidoti A: Fish odor syndrome (trimethylaminuria) supporting the possible FMO3 down expression in childhood: A case report. J Med Case Reports 8: 328, 2014.

22. Sanger F, Nicklen $S$ and Coulson AR: DNA sequencing with chain-terminating inhibitors. Proc Natl Acad Sci USA 74 5463-5467, 1977.

23. Ronaghi M, Uhlén M and Nyrén P: A sequencing method based on real-time pyrophosphate. Science 281: 363, 365, 1998

24. Siqueira JF, Jr., Fouad AF and Rôças IN: Pyrosequencing as a tool for better understanding of human microbiomes. J Oral Microbiol: Jan 23, 2012 (Epub ahead of print). doi: 10.3402/jom. v4i0.10743.

25. Wang X, Zhao J, Wen T, Liao X and Luo B: Predictive value of FMO3 variants on plasma disposition and adverse reactions of oral voriconazole in febrile neutropenia. Pharmacology 106 202-210, 2021
26. Fennema D, Phillips IR and Shephard EA: Trimethylamine and trimethylamine N-Oxide, a flavin-containing monooxygenase 3 (FMO3)-mediated host-microbiome metabolic Axis implicated in health and disease. Drug Metab Dispos 44: 1839-1850, 2016.

27. Chen Y, Weng Z, Liu Q, Shao W, Guo W, Chen C, Jiao L, Wang Q, $\mathrm{Lu} \mathrm{Q}$, Sun $\mathrm{H}$, et al: FMO3 and its metabolite TMAO contribute to the formation of gallstones. Biochim Biophys Acta Mol Basis Dis 1865: 2576-2585, 2019.

28. Li X, Su C, Jiang Z, Yang Y, Zhang Y, Yang M, Zhang X, Du Y, Zhang J, Wang L, et al: Berberine attenuates choline-induced atherosclerosis by inhibiting trimethylamine and trimethylamine-N-oxide production via manipulating the gut microbiome. NPJ Biofilms Microbiomes 7: 36, 2021.

29. Ren W, Zhou C, Liu Y, Su K, Jia L, Chen L, Li M, Ma J, Zhou W, Zhang S, et al: Genetic associations of docetaxel-based chemotherapy-induced myelosuppression in Chinese Han population. J Clin Pharm Ther 45: 354-364, 2020.

30. He YY, Hasan AME, Zhang Q, Li SQ, Yang JS, Yan CX, Chen P, Liu Y, Nadeem A and Zhang B: Novel association between flavin-containing monooxygenase 3 gene polymorphism and antithyroid drug-induced agranulocytosis in the han population. Ann Nutr Metab 74: 200-206, 2019.

31. Ren L, Teng M, Zhang T, Zhang X, Sun B, Qin S, Zhong L, Peng Z and Fan J: Donors FMO3 polymorphisms affect tacrolimus elimination in Chinese liver transplant patients. Pharmacogenomics 18: 265-275, 2017.

32. Chenoweth MJ, Zhu AZX, Sanderson Cox L, Ahluwalia JS, Benowitz NL and Tyndale RF: Variation in P450 oxidoreductase (POR) A503V and flavin-containing monooxygenase (FMO)-3 E158K is associated with minor alterations in nicotine metabolism, but does not alter cigarette consumption. Pharmacogenet Genomics 24: 172-176, 2014.

This work is licensed under a Creative Commons Attribution-NonCommercial-NoDerivatives 4.0 International (CC BY-NC-ND 4.0) License. 